Bannister, J., and O'Sullivan, A. (2013) Civility, community cohesion and antisocial behaviour: policy and social harmony. Journal of Social Policy, 42 (1). pp. 91-110. ISSN 0047-2794

Copyright (C) 2012 Cambridge University Press

A copy can be downloaded for personal non-commercial research or study, without prior permission or charge

The content must not be changed in any way or reproduced in any format or medium without the formal permission of the copyright holder(s)

When referring to this work, full bibliographic details must be given

http://eprints.gla.ac.uk/69841/

Deposited on: 30 May 2013

Enlighten - Research publications by members of the University of Glasgow http://eprints.gla.ac.uk 


\title{
Civility, Community Cohesion and Antisocial Behaviour: Policy and Social Harmony
}

\author{
JON BANNISTER* and ANTHONY O'SULLIVAN** \\ * School of Social and Political Sciences, 25 Bute Gardens, University of Glasgow, Glasgow, \\ G12 8RS \\ email: Jonathan Bannister@glasgow.ac.uk \\ ** School of Social and Political Sciences, 25 Bute Gardens, University of Glasgow, \\ Glasgow, G12 8RS \\ email: Anthony O’Sullivan@glasgow.ac.uk
}

\begin{abstract}
Intergroup conflict, whether manifest as the absence of community cohesion or as the presence of antisocial behaviour, is an issue of international concern. In the UK, confronting the reality or perceived threat of intergroup conflict is a core feature of community cohesion and antisocial behaviour policies. To varying degrees, the frameworks underpinning these policies see the absence or breakdown of community relations as a cause of social disharmony. A key challenge for policy is therefore improvement of the quality of community relations. In this paper, we consider how government has approached this challenge. We filter our analysis through the lens of civility, which proposes that the peaceful coexistence of diverse social groups rests on the existence and maintenance of intergroup empathy and mutual respect. This proposal is supported by international research evidence on the outcomes of meaningful interactions, where these are predicated on equal group status, leading to changes in group and intergroup perceptions and behaviours (the contact hypothesis). We consider the extent to which community cohesion and anti-social behaviour policies in the UK demonstrate a coherent conception of the problem of community relations, the quality of community relations to which these policies aspire and whether the strategies deployed to address community relations seek to support civility through meaningful interaction. We find that the policy debates start from different presumptions concerning the roots of social disharmony, and this is reflected in the nature of the interventions which the community cohesion and antisocial behaviour policy frameworks support. In particular, we find that the social interaction promoted through policies in the UK is not necessarily aimed at achieving social harmony through meaningful interaction based on recognition of equal group status. We also show that these policies are based on little in the way of evidence and prior knowledge.
\end{abstract}

\section{Introduction}

Intergroup conflict, whether manifest as the absence of community cohesion (CC) or as the presence of antisocial behaviour (ASB) is an issue of international concern. Confronting the reality or perceived threat of intergroup conflict is a core feature of both CC policy and ASB policy in the UK (from their inception to date) 
To varying degrees, these policy frameworks portray the absence or breakdown of community relations as a cause of social disharmony, whether this takes the form of a lack of CC or the undertaking of ASB. A key challenge for policy is therefore improvement of the quality of community relations. In this paper, we consider how government has approached this challenge. We filter our analysis through the lens of civility, which proposes that the peaceful coexistence of diverse social groups rests on the existence and maintenance of intergroup empathy and mutual respect. This proposal is supported by international evidence on the outcomes of meaningful interactions, where these are predicated on equal group status (the contact hypothesis). The CC and ASB policy discourses are infused with the rhetoric of civility. We utilise this framework, therefore, to investigate the conception of civility embedded in these discourses and the instruments deployed to achieve its realisation.

Joint examination of the UK CC and ASB policy frameworks is justified on four main grounds. First, both frameworks can be viewed as representative of wider efforts by 'New Labour' administrations (1997-2010) to claim novel political territory. Examining the emergence of the ASB framework, Mooney and Young (2006: 399) comment that 'the Labour Government discovered ... a new territory of concern and a beguiled public found a new crime wave replacing the old'. In discussing the emergence of the CC framework, Robinson (2008: 17) claims that attention 'was steered away from more intractable problems ... and directed towards virgin political territory that the government could colonise with its own priorities and preoccupations', and allies this shift to the rise of a communitarian agenda (see Rose, 1999) wherein the community (or rather community relations) becomes the vehicle through which social harmony can be realised. As the Coalition Government (2010-) begins to articulate its own Big Society agenda (Cabinet Office, 2010), the question emerges as to whether any continuities and discontinuities can be discerned in terms of policy content and overarching agenda.

Second, policy makers see CC and ASB as being connected: weak CC is portrayed as contributing to ASB while ASB is understood to undermine CC. It seems reasonable therefore to assume that $\mathrm{CC}$ and $\mathrm{ASB}$ policies would be based on consistent principles in the way they approach the nurturing of social harmony. In practice, however, the two policy positions are predicated on different views of the causes of social disharmony and adopt distinct approaches to addressing intergroup relations.

Third, both policy frameworks emerged within the context of New Labour enthusiasm for evidence-based policy and practice (Cabinet Office, 1999). Thus, it might be reasonable to expect that robust evidence has been deployed to support the development of these policies. Our reading of the evidence base developed by government does not support this interpretation. Rather, it is limited and narrow in both instances. Moreover, the approaches to managing intergroup relations 
that are embedded in ASB policy are in some regards contrary to what prior knowledge suggests as desirable.

Fourth, looking beyond the UK there is clear evidence that ASB and the lack of CC, manifest in the quality of interactions in the neighbourhood, are issues of concern. In Europe, for example, ASB is perceived to be a growing problem in France, Germany, Spain and the Netherlands, and is closely associated with the 'disrespectful behaviour' of the young (ADT, 2006). Despite widespread endeavours to promote economic and social integration, the persistence of ethnic segregation in Europe has been well documented (Musterd and Van Kempen, 2009). However, there is also evidence from the Netherlands that ethnically diverse neighbourhoods do not necessarily provoke social interaction between native and minority populations. Vervoort (2012), for example, discerned that high levels of ethnic diversity within a neighbourhood may create difficulties for social interaction. Similarly, Gijsberts et al. (2011) found ethnic diversity to have a negative effect on local contacts of all kinds, and more so for the natives than for ethnic minorities. Beyond the recognition of ASB and the lack of CC as international concerns, they are co-joined in policy narratives. For example, though Wacquant (2008) traces distinct forces driving the marginalisation of ethnic minorities and working class populations in the United States and Europe, he makes the case that these groups and their behaviours are positioned in policy discourse as responsible for the economic and social crises encountered in these polities. In a similar vein, Flint (2009: 419) concludes that it is the 'notion that particular urban spaces ... are becoming de-pacified which is a key driver of contemporary concerns about declining social cohesion and civility in Western European polities'.

We develop our argument as follows. The next section considers the concept of civility and the idea of fostering group interaction as a way of promoting social harmony. In the third, we consider the main dimensions of CC policy in light of this discussion and the extent to which it reflects research evidence more broadly. Subsequently, we consider the nature of the relationship between CC and ASB, the evolution and structure of ASB policy in the UK, the implicit view of intergroup relationships that underpins it and the role that evidence has played in the policy setting process. In penultimate section, we consider the following questions: To what extent do CC and ASB policies recognise incivility as underpinning ASB and a lack of CC? Do these policies demonstrate a coherent conception of civility? Is social interaction, and of what type and quality, seen as the solution? In other words, what are the qualities of community relations, of civility, to which these policies aspire? And, what is the role of government in facilitating social interaction and civility seen to be? More generally, we question the nature and quality of the evidence base upon which these policies are based. In the final section, we offer some conclusions. 


\section{Civility, meaningful interaction and social harmony}

Incivility in its different forms reflects poor quality relationships between members of different groups that in turn serve to foment and sustain social disharmony. Incivility may take the form of direct conflict. It can also be embodied in conflicting expectations of social interaction or in the perceptions people hold of other members of society. Thus, social disharmony can be understood as manifest in our behaviours towards and perceptions of others. In contrast, civility can be defined as 'the codes of behaviour that allow us to share public spaces' (Griffith et al., 2011: 10). Such codes of behaviour, akin to Bannister and Kearns' (2009) conception of 'proximate' civility, Somerville's (2009) 'thin' civility and Boyd's (2006: 864) 'formal' civility, reduce civility 'to the manners, politeness, courtesies or other formalities of face-to-face interactions in everyday life'. These interactions include verbal and non-verbal communication; the words and gestures aimed at or used in the presence of others. This conception of civility can be broadened, as often happens implicitly in discussions of incivility, to embrace a wider spectrum of behaviours that impact upon others. Thus, Bannister and Kearns (2009: 180) define 'diffuse' civility as holding 'regard for the effects of our actions and use of space on others with whom we share that space without the condition of direct interaction or of co-presence at a point in time'. ${ }^{1}$

It follows that civility is 'negotiated and maintained through everyday social encounters' (Griffith et al., 2011: 12) and through our actions in public space in the absence of others. However, while these interactions and actions operate as a vehicle for social harmony, they can be characterised as superficial. In these terms, civility enables diverse populations with contrasting identities and preferences, and with no desire or capacity for more meaningful interaction, to peacefully coexist.

These observations prompt consideration of the factors that underpin our willingness, or in some senses capacity, to be civil to others. In part, as Bannister and Kearns (2009) point out, civility is underpinned by an awareness of the other. We require a cultural and social awareness of others to appreciate whether our behaviours and expressions might be offensive to, or reinforce the stereotyping of, others. We also need an awareness of the right to freedom of expression on the part of cultural sub-groups. Such conditions imply the necessity of more meaningful social interaction to stimulate awareness of the other. However, they also depend on the disposition to be open to the presence and inclusion of others.

Whether others are viewed as a legitimate and welcome presence involves acceptance and adjustment on the part of the majority as well as the minority groups. This requires that we revisit our conception of civility. Our appreciation of the legitimacy of others is based on a 'substantive' civility, which 'denotes a sense of standing or membership in the political community with its attendant rights and responsibility' (Boyd, 2006: 864). Under this interpretation, civility 
'presupposes an active and affirmative moral relationship between persons. Being civil is a way of generating moral respect and democratic equality ... civility is a moral obligation borne out of an appreciation of human equality' (Boyd, 2006: $875)$.

In sum, civility is a code of superficial behaviours necessary to enable diverse populations to coexist in harmony, yet the enactment of civility depends upon an awareness of others informed by more meaningful social interaction. These interactions need to be underpinned by recognition of the equality of all citizens. In the absence of these conditions, incivility may take hold. Whether through repeated disregard or institutionalised inequality of status, social groups foster negative feelings toward one another that may develop into hostility and conflict.

Where substantive civility is lacking, the issue then becomes how best to foster it. The idea that increased group interaction forms the basis for improving relations is intuitively appealing and dates back to a number of pioneering social psychology investigations of the 1940s (Pettigrew and Tropp, 2005). The clearest initial exposition is given in Allport's (1954) 'contact hypothesis', a contribution enriched in the 1980 os through the development of social identity theory (Wright et al., 1996).

Allport maintained that intergroup prejudice can be lessened through institutional support for intergroup cooperation based on equality of status between the groups involved (Pettigrew and Tropp, 2005: 264), ${ }^{2}$ and there is general consensus that the contact hypothesis is well supported (Pettigrew and Tropp, 2005; Hewstone, 2009). The situational qualifying conditions are important, as spatial proximity alone does not provoke interaction nor does interaction necessarily engender civility (Flint, 2009). Hewstone and Brown (1986) and Neilsen et al. (2006) have highlighted the requirement of promoting 'pleasant and cooperative' interaction, rather than incidental contact, if intergroup attitudes are to be challenged. More fundamentally, contact involving a lack of perceived equality of status between groups is likely to aggravate rather than ameliorate intergroup prejudice (Allport, 1954: 263; Brewer and Gaertner, 2001: 453), which might reasonably be anticipated to lead to greater incivility and social conflict. Thus, Bakker and Dekker (2012), examining the consequences of a perceived ethnic hierarchy of social position, find that an ethnic group's level of social trust in their neighbours is lower where the share of the next-lowest-placed ethnic group is higher in the neighbourhood, reflecting socioeconomic threat. Trust is also lower where the share of the most distant ethnic group is higher, reflecting cultural threat.

In this section, we have developed a conceptual model of civility in which the notion of fostering social interaction can be seen as a way of promoting social harmony. This model has been grounded in the particular conditions on which this desirable outcome can be expected to materialise, which now enables us to interrogate the CC and ASB policy frameworks. 


\section{Community cohesion policy}

The CC debate in the UK developed in response to racial disturbances in English cities in 2001, though it echoed an earlier concern about cohesion linked to underclass debates. The official report into these disturbances characterised low cohesion areas as being essentially composed of non-interacting social groups leading 'parallel lives [that] often do not seem to touch at any point, let alone overlap and promote any meaningful interchanges' (Home Office, 2001: 9).

Initial efforts to define the cohesive community in detail (LGA, 2002) gave way to a simpler representation that 'community cohesion is what must happen ... to enable different groups of people to get on well together' (CLG, 2008: 4), a shift influenced by the changing preoccupations of the CC agenda. CC as a policy construct therefore lays emphasis on the quality of social interaction as the key to enhancing cohesion (Home Office, 2001). Home Office guidance confirmed government acceptance of the importance of fostering substantive civility: 'community cohesion can only grow when society as a whole recognises ... the right to equality ... [and] respects and appreciates the diverse nature of our communities' (Home Office, 2005: 3).

Taking the conclusion on parallel lives at face value (though there are robust critiques of its evidential base, Simpson, 2004; Dorling and Rees, 2003) and a policy desire to replace it with more integrated communities, government could in principle formulate its response in a number of alternative ways in terms of the nature of the role it adopts itself or gives to nominated agencies. First, government could attempt to mediate between groups, addressing community tensions on a bilateral basis but with no direct attempt to bring the groups together. A second approach would involve government acting as a facilitator, playing the role of honest broker in the search for forms of mutual engagement. A third alternative would see government creating space (physical or metaphorical) for groups to constructively explore and address problems for themselves, essentially playing the role of supervisor. The final and least active alternative would see government adopting a laissez-faire approach, expecting groups to figure things out for themselves, acting only as an observer. These alternatives are summarised in Figure 1. Our reading of the contact hypothesis suggests the most productive option would be the second approach. To a lesser extent, an argument might also be made for the third approach on this basis, but it would be hard to make any kind of case for the other two.

Initial agency roles in the promotion of (racial) cohesion were articulated as facilitating interaction, mediation and the protection of victimised minority groups (Home Office, 2001). Central government subsequently established local government (community planning) as the primary instrument for taking the lead in addressing social cohesion more generally (based on duties imposed through the Local Government Act 200o) and assigned itself a strategic role. ${ }^{3}$ In practice, 
Mediator

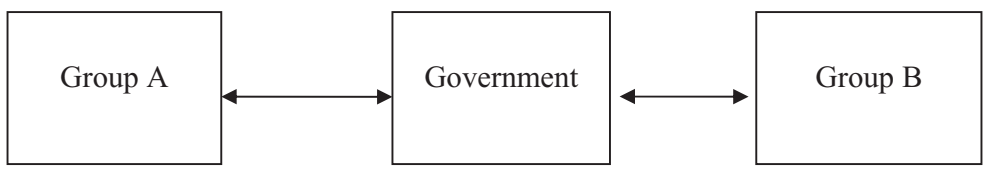

Facilitator

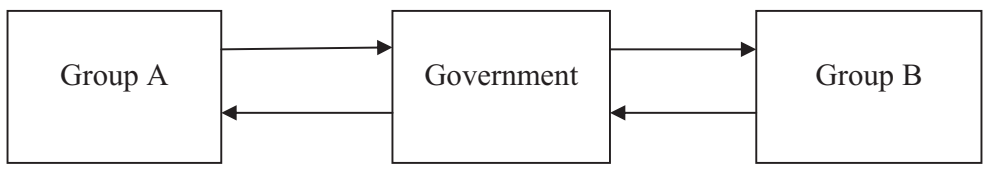

Supervisor

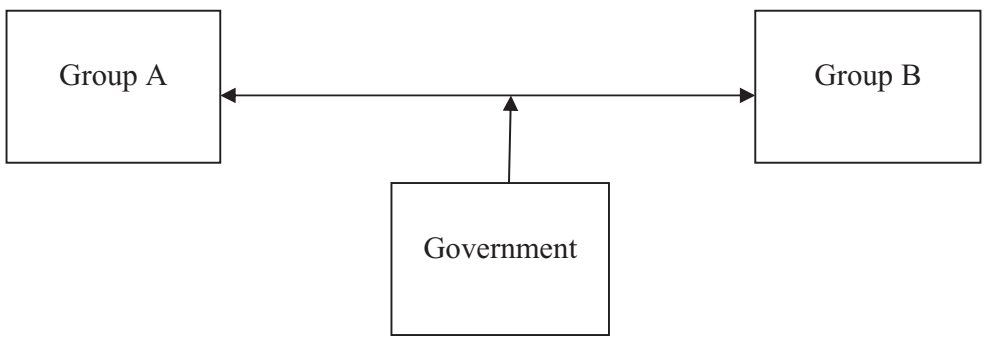

Observer
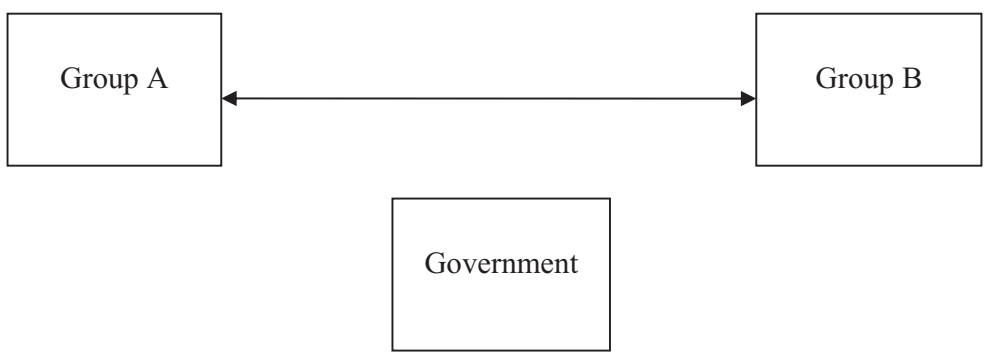

Figure 1. Types of Engagement 
these arrangements have proved to be largely consistent with a 'supervisory' and to a lesser extent 'observer' based interpretation of government responsibilities, where this extends to providing meaningful spaces within which groups can engage, but not to directing the precise nature of that engagement (Home Office, 2005; Commission on Integration and Cohesion, 2007; Broadwood and Sugden, 2009; CLG, 2008, 2009).

The Coalition Government has sought to redefine the framework for promoting CC (CLG, 2012) in line with its Big Society agenda. Its intention is that central government will act only exceptionally, with the aim being to encourage and support others to specify, deliver and fund interventions. Identifying the establishment of 'common ground', defined as shared aspirations and values, as a key factor contributing to integration, a range of illustrative initiatives is identified including the 'Big Lunch', a voluntary and private sector initiative which aims to encourage neighbourly interaction through communal eating. It is too early to judge the impact of initiatives such as this upon CC. However, there is a clear resonance with New Labour's approach. First, significant emphasis is placed upon locally led action. Second, the proposals are consistent with a 'supervisory-' and 'observer-' based interpretation of government responsibilities. ${ }^{4}$

As to the role of evidence within the policy process (1997-2010), the Citizenship Survey (terminated in 2011) was used to measure CC and by extension the efficacy of policy (Home Office, 2003a). In particular, the overall degree of CC was determined by the percentage of people who said they felt that their local area was a place where people from different backgrounds could get on well together. Although government is able to claim some success on this measure, with the proportion of respondents agreeing with the statement increasing from 80 per cent in 2003 to 86 per cent in 2010-11 (CLG, 2010: 1), its meaning and relevance are highly debatable, given the conceptual ambiguity of terms such as 'local area' and 'background' (Fuller, 2011).

With the official measure as the dependent variable, Laurence and Heath (2008) used a multi-level modelling approach to identify individual- and community-based predictors of CC. Unsurprisingly, deprivation was found to be strongly associated with lack of CC. Once other factors had been accounted for, ethnic diversity in an area was found in most cases to be a positive driver of $\mathrm{CC}$, which was taken as evidence of a social dynamic consistent with the contact hypothesis (Laurence and Heath, 2008: 43-4). While the authors also found that in-migration can decrease cohesion if large proportions of the in-migrants are non-white and originate from outside the UK, they speculate that areas subject to an influx of ethnic in-migrants may initially experience a decrease in CC that ameliorates over time as interaction increases and residents acclimatise (Laurence and Heath, 2008: 45). Lacking time-series data, the authors were unable to test for this. 
Further analysis (using the same suspect dependent variable) confirmed a strong, positive association between cohesion and affluence, with rurality and the presence of community facilities also demonstrating positive correlation (DTZ, 2007). Negative correlation was found to exist between cohesion levels, the extent of A8 immigration and the presence of local industrial decline, but no single encompassing model of cohesion was found to apply equally across the regions of England. DTZ (2007) acknowledged the approach taken throws no light on underlying causal relationships and mechanisms. Its analysis therefore does not support conclusions about what policies work at local and community levels. However, policy has not appealed to rigorous research in this regard. Initial CC policy positions were predominantly informed by interviews undertaken with interested parties within the areas in which the racial disturbances took place (Home Office, 2001). A subsequent practitioner's toolkit drew on the experience of a number of 'pathfinders', but in a way that has lacked analytical rigour (Home Office, 2005). At the same time, the officially constituted 'Community Cohesion Panel' expressed that it would be 'impossible to develop responsible public policies without much better data on community dynamics' (CLG, 2004: 17).

The subsequent official Commission on Integration and Cohesion (20067), charged with developing practical solutions to building cohesion at a local level, drew heavily on 'regional visits, round tables and stakeholder consultations' (CLG, 2008: 6). The Commission was also informed by qualitative investigation in a small number of case study areas (Ipsos-Mori, 2007). The Commission duly found the 'complexity and locally-specific nature of cohesion ... raises real questions about how policy should be developed and monitored ... With few best practice approaches, or evidence grounded project models to draw on ... local agencies could certainly benefit from further support and guidance from the centre on strategic approaches' (Ipsos-Mori, 2007: 13). While Orton (2009) has subsequently used the contact hypothesis to interpret the experience of community practitioners, he nevertheless concludes that the development of improved interactions should remain understood as a long-term process involving art rather than science (Orton, 2009: 63).

Finally, we should note that there has been no meaningful evaluation of CC policy interventions. As Ratcliffe and Newman (2011: 2) point out, this was surprising given New Labour's enthusiasm for evidence-based policy. In sum therefore, CC policy has been founded on the reasonable principle that increasing civility is an essential precondition for improving CC. In promoting CC, government (1997-2012) has come to interpret its role as largely 'supervisory' in nature. The work New Labour commissioned into the determinants of cohesion may have thrown light on individual and community predictors of areas with high or low levels of cohesion, but not on the underlying causal processes, or the practical policy responses required to promote cohesion. 


\section{Antisocial behaviour policy}

Although the idea of CC in UK public policy developed from an initial concern with race relations, it was understood to be an encompassing policy concept involving a range of specific fields, including youth, equalities, policing, regeneration and housing. Within this framework, ASB is seen as a factor that contributes to poor social cohesion, because it can make people afraid to go out or visit certain places, and because the public resentment caused by the experience of ASB can lead some people to make scapegoats of social groups from which the perpetrators of ASB are perceived to be drawn (Home Office, 2005: 33). Likewise, the Scottish Government has articulated a range of specific ways in which reduced ASB increases CC and vice versa (Scottish Government, 2009a). This belief on the part of UK and Scottish Governments has been maintained in spite of the fact that the relationship between ASB and CC remains poorly understood, with little in the way of research evidence to illuminate matters (Commission on Integration and Cohesion, 2007: 28).

ASB is formally defined by the Crime and Disorder Act 1998 as acting in a manner that caused or was likely to cause harassment, alarm or distress to one or more persons not of the same household (as the perpetrator)'. Clearly, this definition is open to broad interpretation (Harradine et al., 2004; Millie, 2008) and what one person interprets as harassment, alarm or distress may be of little consequence to another. In practice therefore, the experience of ASB is as much about expectations of the nature of social interaction and the qualities of public spaces (Millie, 2008) as it is about actual victimisation (Von Hirsch and Simester, 2006). In this instance, government has again argued 'the need for a cultural shift ... that the rights we all enjoy are based in turn on the respect and responsibilities we have to other people and to our community' (Home Office, 2003b: 6). However, as applied to ASB policy, this sentiment was qualified by the observation that 'respect cannot be learned, purchased or acquired, it can only be earned' (Respect Task Force, 2006: 30). In other words, ASB policy under New Labour demanded those deemed not to comply with social norms to act in a respectable manner. For Somerville (2009: 149), this devalues and disrespects all those who have not managed to "'earn" the respect of others'. The inherent inequality that pervaded the ASB agenda led Millie (2009: 8) to conclude that 'the government has produced a dichotomised view of a respectful, law abiding "us" and an anti-social, disrespectful "them"'. Put otherwise, in contrast to CC policy, ASB policy has supported the institutionalised denial of equal status across groups even though at least some of the behaviours exhibited by 'antisocial offenders' would be acceptable in other social and spatial contexts.

In practice, ASB policy addresses four broad types of behaviour (misuse of public space, disregard for community/personal wellbeing, acts directed at people and environmental damage) through four broad types of response; individual focused, housing related, parenting related and geographically focused 
(Clarke et al., 2011). Within this framework, the emphasis on punishment and rehabilitation has varied across time and space. In England and Wales, the reach of antisocial behaviour orders (ASBOs) introduced through the Crime and Disorder Act 1998 was broadened through the Antisocial Behaviour Act 2003. By 2007, ASBOs had fallen into political disfavour with the Labour Government, which chose instead to put increasing emphasis on early intervention measures (Hodgkinson and Tilley, 2011). The election of a Coalition Government in 2010 marked a renewed appetite for enforcement measures, but with more 'flexibility' and 'accountability' (Home Office, 2011). Reflecting on the measures outlined in this consultation document, which were closely mirrored in the subsequent White Paper (Home Office, 2012), Hodgkinson and Tilley (2011: 295) discern that despite some improvements in codification, it is possible to conclude that 'that this is largely an exercise in "rebranding" whereby similar results will be achieved by very similar tools'.

The trajectory of policy in Scotland, where a newly devolved administration accepted responsibility for dealing with ASB in 1999, has been different. The 1998 policy framework inherited from Westminster was strengthened through publication of a national ASB strategy (Scottish Executive, 2003) and passage of the Criminal Justice (Scotland) Act2003 and the Antisocial Behaviour etc. (Scotland) Act 2004. The framework was then revisited (Scottish Government, 2009a, 2009b, 2009c) at which point considerable emphasis was placed on a movement away from sanctions against perpetrators in favour of prevention and this emphasis is currently maintained.

Despite these differences in country-level policy trajectory and emphasis, UK ASB policy has remained consistently founded on government sponsored intervention to protect and defend aggrieved groups and to change the behaviour patterns of perpetrator groups (mediated engagement in terms of Figure 1). While policy makers have on occasion proposed an active role for aggrieved groups in the management or dissipation of ASB activity (facilitated engagement in terms of Figure 1), this has not been accepted as desirable by these groups themselves, who prefer mediated arrangements to be maintained (Home Office, 2011; Scottish Government, 2009a).

Crawford (2008) argues that, on balance, the symbolic and communicative properties of the ASB framework (in England and Wales) and the endeavours to convince the public that government was acting to address public anxieties seriously were more salient than the appropriateness or effectiveness of the ASB strategies themselves. The oversight of the framework, therefore, was restricted to the collation of limited data on the use of powers and the 'crude monitoring of public perceptions' (Crawford, 2008: 754) of ASB via the British Crime Survey (England and Wales). Assessing these data, and in particular the perception that the behaviours of young people are perceived as a problem, Tonry and Bildsten (2009: 586) assert that 'if the British Crime Survey results are seen as 
a proxy measure, the conclusion would have to be that antisocial behaviour increased after 1998'. More generally, the spectrum of public perceptions about the extent of ASB, as measured through the British Crime Survey and the Scottish Crime and Justice Survey, improved between 1999 and 2010 (Chaplin et al., 2011; Scottish Government, 2011) but the extent to which this reflects evidencebased policy is a moot point. In England and Wales, some seven years after the introduction of the ASB policy framework, most of the data used for planning and monitoring ASB initiatives were not sufficiently disaggregated to support effective targeting (Audit Commission, 2006: 16), there was no robust evidence of the cost effectiveness of ASB interventions on an area basis (Audit Commission, 2006: 34), while comparable local areas were using different approaches and 'there has been no comparative evaluation of the success of these approaches (nor) evaluation of the use and success of the different measures and powers, making it difficult ... to assess what works best' (House of Commons Committee of Public Accounts, 2007: 3). ${ }^{5}$ Clarke et al. (2011) conclude that 'current ASB data collection practice does not tend to generate the kinds of data-sets which can underpin robust assessments of the effectiveness of ASB interventions' (Clarke et al., 2011: 22).

The most recent reconfiguration of English ASB policy claims to be based on evidence of 'what works', but does not supply explicit details about what this is (Home Office, 2011: 9). The corresponding Scottish policy review is more diligent in this regard, and drew on investigations into the use of ASBOs (DTZ and HeriotWatt University, 2007), the use of Dispersal Orders (Cavanagh, 2007), evaluations of local authority neighbour noise nuisance services (Evans et al., 2007), the implementation of neighbourhood strategies (Flint et al., 2007), community warden schemes (Hayton et al., 2007) and intensive family support projects (Pawson et al., 2009). In the round, these studies offer quantification of the use of various policy instruments over time, together with limited attempts at initial assessment of intervention efficacy and cost effectiveness (Scottish Government, 2009c). Practitioner evidence collected within and alongside these studies played the decisive role in the above-noted Scottish policy shift, which de-emphasised the role of enforcement in favour of a more holistic approach encompassing additional prevention, intervention and rehabilitation measures. It is also notable that the essentially coterminous 'evidence-led' reviews in England and Scotland have resulted in considerable differences of policy emphasis.

\section{Civility, interaction, the role of government and evidence}

We have argued that a lack of CC and the occurrence of ASB reflects poor intergroup relations and perceptions; on the other hand, that civility reflects and maintains harmonious relations, though it needs to be underpinned by acceptance of the legitimacy and equal status of others (Boyd, 2006; Somerville, 
2009). This offers a starting point for assessing the CC and ASB policy frameworks in the UK.

CC policy identifies social interaction as the key to enhancing CC. In terms of the situational conditions for reducing intergroup tensions discussed in the second section, the importance of equality of status is well reflected in the policy debate (Cantle, 2008) and institutional sanction is evident, but the policy framework places insufficient emphasis on actively promoting intergroup cooperation. Local government has been assigned the primarily passive role of providing spaces within which people can engage (Commission on Integration and Cohesion, 2007), but the policy framework is permissive and suggestive, rather than definitive and prescriptive, and central government has been prepared to offer only the most general and abstract advice (Home Office, 2005; Broadwood and Sugden, 2009; CLG, 2009). Developments in the policy framework have been informed by a modicum of evidence and there are legitimate question marks over the comprehensiveness and robustness of this evidence. There has been limited investigation of effective ways to promote CC, limited monitoring of change in levels of CC and scant investigation of the effectiveness of policy (Orton, 2009).

ASB policy is also bereft of evidential underpinnings. There is little research to inform debate, question marks (at least in England) over the effectiveness of policy targeting and even doubts about the veracity of activity monitoring data (Audit Commission, 2006; House of Commons Committee of Public Accounts, 2007; Clarke et al., 2011). Recent Scottish developments with respect to ASB policy are more credibly based on research, but even here the latter has involved the evaluation of short-term initiatives, buttressed by a heavy reliance on qualitative practitioner views on 'what works' (Scottish Government, 2009c). Whether this approach would satisfy higher standards of proof is extremely doubtful (Bond et al., 2011).

More fundamentally, ASB policy is founded on a different understanding of intergroup relations than CC policy. In particular, the policy framework does not presume equality across social groups. Rather it is based on an inequality of status arising from a judgement of behaviour. Designation of individuals as perpetrators or victims of ASB implies some degree of ostracism of the former for failing to comply with accepted social norms. But ASB is not about crime per se, it is about perceptions of the social acceptability of various forms of group activity and interaction (Squires, 2008). As such, a critical issue is what makes certain behaviours unacceptable and why. This consideration is largely absent from the ASB policy debate. The agenda here is not the promotion of mutual respect in a diverse society but the earning of respect by those currently outside a common value system, even if this system remains unspecified. ASB is most commonly associated with the behaviours of youth. Bannister and Kearns (forthcoming) demonstrate how current perceptions of youth are underpinned by a growing intolerance resulting from economic and social trends that foment 
social disconnectedness, leading to the stereotyping of youth and their presence in public space being read as a metaphor of social decay. By formalising and legitimising this interpretation, in the process imposing a relation of inequality between youth and other social groups, ASB policy acquired the capacity to establish a vicious cycle of intolerance and to diminish civility.

Whereas CC policy favours either supervised or unsupported types of engagement between social groups, ASB policy places greater emphasis on mediated arrangements (Figure 1). More specifically, ASB policy has cast government and its agencies in the roles of bulwark for the protection and defence of aggrieved groups and to shepherd the errant back to the fold of mainstream conformity. Those formally responsible for dealing with ASB generally see the primary purpose of interventions as protection of victim groups (Clarke et al., 2011: 21), even if this is attained through targeting perpetrators. While policy has attempted to foster community roles in the overall management of ASB initiatives in the belief that solutions will be led by 'empowered individuals, parents and communities who are prepared to stand up and challenge it' (Home Office, 2011: 27), victim groups and the wider general public have remained reluctant to get involved. The pertinent point is that the policy framework is not about the promotion of equal intergroup cooperation or the nurturing of civility.

While policy makers have recognised that a link exists between CC and ASB, in practice they have not explored the nature of that link to any great extent. More generally the CC and ASB policy frameworks do not address the notion of civility or the mechanisms for enhancing it. In consequence, the development of the CC and ASB frameworks, involving (essentially) the same government interests, display a distinct lack of articulation with one another.

\section{Conclusions}

Policy concern with levels of CC and ASB in the UK reflect problems arising from the quality of relations between various social groups and involve a deficit of formal and substantive civility. The policy frameworks developed within the UK to address CC and ASB would, in an ideal world, recognise the relational nature of the problems they seek to address and draw upon what is already known to work effectively in the promotion of social harmony. Importantly, this would include equality of status in intergroup contact, development of cooperation in the pursuit of common goals and institutional support. CC policy, while not exactly promoting meaningful and purposeful social interaction, does at least recognise that the underlying issue is relational in nature and respects the importance of equality of intergroup status in contact situations. These latter attributes are conspicuous by their absence from the ASB policy framework, which in many instances acts to legitimise intolerance and unequal group status, particularly with respect to young people. More generally, the forms 
of group interaction promoted by ASB policy are largely indirect rather than direct in nature, with government and state agencies acting (as mediators or facilitators) on behalf of those perceiving ASB to rehabilitate or punish perceived perpetrators. Attempts by government to increase the role of victims of ASB in the management and implementation of local policy initiatives have been misconceived to the extent that they reinforce the idea of unequal status across social groups, and have in any case been met with indifference. While CC policy promotes direct contact between groups, it seeks more to supervise such contact than actively facilitate it, which may have been to the detriment of overall policy impact.

Being largely contemporaneous, CC and ASB policies emerged and evolved in an era marked by a new emphasis on the importance of evidence. Policies, in consequence, are expected to demonstrate in a robust way both the nature of the problems that they are designed to address and their efficacy once implemented. Sadly, neither CC nor ASB policy can be held up as beacons in these regards. In terms of scoping and reforming initial policy positions, the evidence base in both instances predominantly made uncritical appeal to practitioner views and the results from short-term evaluation initiatives. More fundamentally, where research has been used to support ASB policy development and its implementation this has been configured in a way that has reinforced rather than questioned policy maker presumptions about the forms of engagement that policy should promote.

It is possible that CC policy may have improved some dimensions of CC while ASB policy has been pulling in an altogether different direction. CC policy may have enhanced civility (though we find little evidence of this), but ASB policy will have if anything (based on its formulation) decreased it and may have contributed to a vicious cycle of intolerance. Recent European Quality of Life Survey (EQLS) data (which covers all twenty-seven EU member states, Norway and the candidate countries of Croatia, the Former Yugoslav Republic of Macedonia and Turkey) suggest levels of racial and intergenerational tension in the UK are close to the average for Europe as a whole. In 2007, some 40 per cent of survey respondents in the UK perceived a lot of tension in racial and ethnic relations, and 18 per cent a lot of tension in relations between young and old persons (Rose and Newton, 2010: 42; Anderson et al., 2009: 57). The policy ideal in this context would be the establishment of a virtuous cycle of increasing civility through meaningful engagement between groups. CC policy could be reconfigured to deliver this through a more purposive approach. ASB policy would need more radical surgery, based on a reassessment of the way it approaches the status of different social groups. Practical development of both these recommendations would also benefit from a more robust evidence base, built upon a richer appreciation of the foundations of civility. Finally, the international recognition of intergroup conflict is suggestive of the potential that 
our policy recommendations may hold in other European polities. A key starting point that this observation provokes, however, is the need for future research to consider the conceptual drivers and evidential underpinnings of CC and ASB policies within these jurisdictions.

Looking forward, we can begin to discern elements of continuity and discontinuity between the New Labour agenda and that of the Coalition Government's Big Society as manifest in the frameworks (and evidential underpinnings) for CC and ASB. Wells (2011) and Taylor (2011) have observed that the Coalition's emphasis on the promotion of civil society is closely related to the ideas of social capital and communitarianism underpinning New Labour's public policies. That said, commentators have argued that the goals of increasing localism and community empowerment are unlikely to be achieved when set in relation to the austerity measures deployed and the broader ideological goals of the Coalition of state retrenchment and increased marketisation (Taylor, 2011; Sullivan, 2012).

The CC and ASB frameworks of the Coalition Government, despite protestation of novelty, also resonate with those of the Labour Government. In relation to $\mathrm{CC}$, the emphasis on creating meaningful spaces for interaction in the hope of establishing 'common ground', allied to an emphasis upon locally led and funded action is consistent with a 'supervisory-' and 'observer-' based interpretation of government responsibilities. In relation to ASB, there is a continuation of emphasis on community engagement, community problemsolving and community mobilisation (Hodgkinson and Tilley, 2011); thus it is intended that the community are 'able to make decisions and take the lead in making change happen, with agencies available to assist' (Home Office, 2011: 11). Yet, matching Labour's message that it was the state's responsibility to intervene in ASB, it appears that the Coalition intend to retain a role as 'mediator' and/or 'facilitator'. In light of concerns as to whether the voluntary and business sectors will be able or want to contribute to achieving the goals of these frameworks, the government has launched Big Society Capital (Watt, 2012), which challenges charities and social enterprises to 'prove their business models and then replicate them' in order to create 'a self-sustaining, independent market that's going to help build the Big Society'. Whether this new business model and fund will succeed in delivering social harmony is uncertain as it has to be set against the extent of recent public and third sector expenditure cuts (Curtis, 2010).

\section{Notes}

1 See also Somerville's (2009) conception of 'thick' civility in this regard.

2 Social identity theory has largely concerned itself with why this might be the case - that is to say the processes through which contact works (Kenworthy et al., 2005).

3 As the more general policy framework defining the relationship between central and local government developed over the period 2000-2011, the channels through which cohesion 
policy initiatives operated also evolved - to include 'local strategic partnerships' and 'local area agreements'.

4 The CC framework is identified as being consistent with the ASB framework (Home Office, 2012) and the Localism Act 2011.

5 Rubin et al. (2006) assess the absence of evaluation of antisocial behaviour programmes to be a Europe wide issue.

\section{References}

ADT (2006), Anti-Social Behaviour across Europe, www.adt.pt/informacao-corporativa/ AntiSocialBehavioUrAcrossEurope_EN.pdf

Allport, G. W. (1954), The Nature of Prejudice, Cambridge, MA: Addison-Wesley.

Anderson, R., Branislav, M., Vermeylen, G., Lyly-Yrjanainen, M. and Zigante, V. (2009), Second European Quality of Life Survey Overview, Dublin: European Foundation for the Improvement of Living and Working Conditions.

Audit Commission (2006), Neighbourhood Crime and Anti-Social Behaviour: Making Places Safer through Improved Local Working, London: Audit Commission.

Bannister, J. and Kearns, A. (2009), 'Tolerance, respect and civility amid changing cities', in A. Millie (ed.), Securing Respect: Behavioural Expectations and Anti-Social Behaviour in the UK, Bristol: Policy Press, pp. 171-92.

Bannister, J. and Kearns, A. (forthcoming), 'Overcoming intolerance to young people's conduct: implications from the unintended consequences of policy in the UK', Criminology and Criminal Justice, DOI: 10.1177/1748895812458296' following 'Justice'.

Bakker, L. and Dekker, K. (2012), 'Social trust in urban neighbourhoods', Urban Studies, 49.

Bond, L., Sautkina, E. and Kearns, A. (2011), 'Mixed messages about mixed tenure: do reviews tell the real story?', Housing Studies, 26: 69-94.

Boyd, R. (2006), 'The value of civility?', Urban Studies, 43: 863-78.

Brewer, M. and Gaertner, S. L. (2001), 'Toward reduction of prejudice: intergroup contact and social categorization', in R. Brown and S. L. Gaertner (eds.), Blackwell Handbook of Social Psychology: Intergroup Processes, Oxford: Blackwell Publishers, pp. 451-72.

Broadwood, J. and Sugden, N. (2009), Building Cohesive Communities What Frontline Staff and Community Activists Need to Know, London: Communities and Local Government.

Cabinet Office (1999), Professional Policy Making for the 21st Century, Report by the Strategic Policy Making Team, Cabinet Office, London: Stationery Office.

Cabinet Office (2010), Building the Big Society, London: The Cabinet Office.

Cantle, T. (2008), Community Cohesion: A New Framework for Race and Diversity, Basingstoke: Palgrave Macmillan.

Cavanagh, B. (2007), A Review of Dispersal Power, Edinburgh: Scottish Government Social Research.

Chaplin, R., Flatley, J. and Smith, K. (2011), 'Crime in England and Wales 2010/11', Home Office Statistical Bulletin, 10/11, London: Home Office.

Clarke, A., Williams, K., Wydall, S., Gray, P., Liddle, M. and Smith, A. (2011), Describing and Assessing Interventions to Address Anti-Social Behaviour, Research Report 51, London: Home Office.

Commission on Integration and Cohesion (2007), Our Shared Future, Wetherby: Commission on Integration and Cohesion.

Communities and Local Government (CLG) (2004), The End of Parallel Lives? The Report of the Community Cohesion Panel, London: Communities and Local Government.

Communities and Local Government (CLG) (2008), The Government's Response to the Commission on Integration and Cohesion, London: Department for Communities and Local Government.

Communities and Local Government (CLG) (2009), Guidance on Meaningful Interaction: How Encouraging Positive Relationships Between People Can Help Build Community Cohesion, Wetherby: Communities and Local Government. 
Communities and Local Government (CLG) (2010), Cohesion Delivery Framework Overview, London: Communities and Local Government.

Communities and Local Government (CLG) (2012), Creating the Conditions for Integration, London: Communities and Local Government.

Crawford, A. (2008), 'Dispersal powers and the symbolic role of anti-social behaviour legislation', The Modern Law Review, 71: 753-84.

Curtis, P. (2010) 'Axe on charities "risks wrecking big society", The Guardian, 24 October.

Dorling, D. and Rees, P. (2003), 'A nation still dividing: the British census and social polarisation 1971-2001', Environment and Planning A, 37: 1287-313.

DTZ (2007), Evidence on Integration and Cohesion: Phase Two, Wetherby: Communities and Local Government.

DTZ and Heriot-Watt University (2007), Use of Antisocial Behaviour Orders in Scotland, Edinburgh: Scottish Government Social Research.

Evans, A., Boyle, J., Gardner, S., Hay, C. and Patterson, K. (2007), An Evaluation of Local Authority Antisocial Neighbour Noise Nuisance Services, Edinburgh: Scottish Government Social Research.

Flint, J. (2009), 'Cultures, ghettos and camps: sites of exception and antagonism in the city', Housing Studies, 24: 417-31.

Flint, J., Green, S., Hunter, C., Nixon, J., Parr, S., Manning, J., Wilson, I., Pawson, H., Davidson, E. and Sanderson, D. (2007), The Impact of Local Antisocial Behaviour Strategies at the Neighbourhood Level, Edinburgh: Scottish Government Social Research.

Fuller, C. (2011), 'Measuring performance in community cohesion', in I. Newman and P. Radcliffe (eds.), Promoting Social Cohesion: Implications for Policy and Evaluation, Bristol: Policy Press, pp. 61-80.

Gijsberts, M., van der Meer, T. and Dagevos, J. (2011), "Hunkering down” in multi- ethnic neighbourhoods? The effects of ethnic diversity on dimensions of social cohesion', European Sociological Review, DOI: 10.1093/esr/jcr/022.

Griffith, P., Norman, W., O'Sullivan, C. and Ali, R. (2011), Charm Offensive: Cultivating Civility in 21st Century Britain, London: The Young Foundation.

Harradine, S., Kodz, J., Lernetti, F. and Jones, B. (2004), Defining and Measuring Antisocial Behaviour, Home Office Development and Practice Report 26, London: Home Office.

Hayton, K., Boyd, C., Campbell, M., Crawford, K., Latimer, K., Lindsay, S. and Percy, V. (2007), Evaluation of the Impact and Implementation of Community Wardens, Edinburgh: Scottish Executive Social Research.

Hewstone, M. (2009), 'Living apart, living together? The role of intergroup contact in social integration', Proceedings of the British Academy, 162: 243-300.

Hewstone, M. and Brown, R. (1986), Contact and Conflict in Intergroup Encounters, New York: Basil Blackwell.

Hodgkinson, S. and Tilley, N. (2011), 'Tackling anti-social behaviour: lessons from New Labour for the Coalition Government', Criminology and Criminal Justice, 11: 283-305.

Home Office (2001), Community Cohesion: A Report of the Independent Review Team, London: The Home Office.

Home Office (2003a), Building a Picture of Community Cohesion: A Guide for Local Authorities and their Partners, London: The Community Cohesion Unit.

Home Office (2003b), Respect and Responsibility - Taking a Stand Against Anti-Social Behaviour, Norwich: The Stationery Office.

Home Office (2005), Community Cohesion: SEVEN STEPS A Practitioner's Toolkit, London: The Home Office.

Home Office (2011), More Effective Responses to Antisocial Behaviour, London: Home Office.

Home Office (2012), Putting Victims First: More Effective Responses to Antisocial Behaviour, London: Home Office.

House of Commons Committee of Public Accounts (2007), Tackling Anti-Social Behaviour, Forty-fourth Report of Session 2006-07, London: The Stationery Office. 
Ipsos-MORI (2007), What Works' in Community Cohesion, Research Study Conducted for Communities and Local Government and the Commission on Integration and Cohesion, London: Communities and Local Government.

Kenworthy, J. B., Turner, R. N., Hewstone, M. and Voci, A. (2005), 'Intergroup contact: when does it work and why?', in J. F. Dovidio, P. Glick and L. A. Rudman (eds.), On the Nature of Prejudice: Fifty Years after Allport, Oxford: Blackwell Publishing, pp. 278-92.

Laurence, J. and Heath, A. (2008), Predictors of Community Cohesion: Multi-Level Modelling of the 2005 Citizenship Survey, London: Communities and Local Government.

Local Government Association (LGA) (2002), Guidance on Community Cohesion, London: LGA Publications.

Millie, A. (2008), 'Anti-social behaviour, behavioural expectations and an urban aesthetic', British Journal of Criminology, 48: 379-94.

Millie, A. (2009), Anti-Social Behaviour, Maidenhead: Open University Press.

Mooney, J. and Young, J. (2006), 'The decline in crime and the rise in anti-social behaviour', The Journal of Community and Criminal Justice, 53: 397-407.

Musterd, S. and Van Kempen, R. (2009), 'Segregation and housing of minority ethnic groups in Western European cities', Tijdschrift voor Economische en Sociale Geografie, 100: 55966.

Orton, A. (2009), What Works in Enabling Cross-Community Interactions? Perspectives on Good Policy and Practice, Wetherby: Communities and Local Government.

Neilsen, I., Nyland, C., Smyth, R., Zhang, M. and Zhu, C. (2006), 'Effects of intergroup contact on attitudes of Chinese urban residents to migrant workers', Urban Studies, 43: 475-90.

Pawson, H., Davidson, E., Sosenko, F., Flint, J., Nixon, J., Casey, R. and Sanderson, D. (2009), Evaluation of Intensive Family Support Projects in Scotland, Edinburgh: Scottish Government Social Research.

Pettigrew, T. F. and Tropp, L. R. (2005), 'Allport's intergroup contact hypothesis: its history and influence', in J. F. Dovidio, P. Glick and L. A. Rudman (eds.), On the Nature of Prejudice: Fifty Years after Allport, Oxford: Blackwell Publishing, pp. 262-77.

Ratcliffe, P. and Newman, I. (2011), Promoting Social Cohesion: Implications for Policy and Evaluation, Bristol: Policy Press.

Respect Task Force (2006), Respect Action Plan, London: Home Office.

Robinson, D. (2008), 'Community cohesion and the politics of communitarianism', in J. Flint and D. Robinson (eds.), Community Cohesion in Crisis? New Dimensions of Diversity and Difference, Bristol: Policy Press, pp. 15-34.

Rose, N. (1999), 'Inventiveness in politics', Economy and Society, 28: 467-93.

Rose, R. and Newton, K. (2010), Evaluating the Quality of Society and Public Services, Dublin: European Foundation for the Improvement of Living and Working Conditions.

Rubin, J., Rabinovich, L., Hallsworth, M. and Nason, E. (2006), Interventions to Reduce Antisocial Behaviour and Crime: A Review of Effectiveness and Costs, Pittsburgh: RAND.

Scottish Executive (2003), Putting Our Communities First, Edinburgh: TSO.

Scottish Government (2009a), Promoting Positive Outcomes: Working Together to Prevent Antisocial Behaviour in Scotland, Volume 1, Edinburgh: Scottish Government.

Scottish Government (2009b), Promoting Positive Outcomes: Working Together to Prevent Antisocial Behaviour in Scotland, Volume 1 Annexes, Edinburgh: Scottish Government.

Scottish Government (2009c), Promoting Positive Outcomes: Working Together to Prevent Antisocial Behaviour in Scotland, Volume 2, Edinburgh: Scottish Government.

Scottish Government (2011) Scotland's People, Edinburgh: Scottish Government.

Simpson, L. (2004), 'Statistics of racial segregation: measures, evidence and policy', Urban Studies, 41: 661-81.

Somerville, P. (2009), “'The feeling's mutual”: respect as the basis for cooperative interaction', in A. Millie (ed.), Securing Respect: Behaviour Expectations and Anti-Social Behaviour in the UK, Bristol: Policy Press, pp. 139-70.

Squires, P. (2008), ASBO Nation: The Criminalisation of Nuisance, Bristol: Policy Press.

Sullivan, H. (2012), 'A Big Society needs an active state', Policy and Politics, 40: 145-8. 
Taylor, M. (2011), 'Community organising and the Big Society: is Sail Alinsky turning in his grave?', Voluntary Sector Review, 2: 257-64.

Tonry, M. and Bildsten, H. (2009), 'Antisocial behaviour', in M. Tonry (ed.), Crime and Public Policy, Oxford: Oxford University Press, pp. 578-98

Vervoort, M. (2012), 'Ethnic concentration in the neighbourhood and ethnic minorities'social integration: weak and strong social ties examined', Urban Studies, 49: 897-916.

Von Hirsch, A. and Simester, A. P. (2006), Incivilities: Regulating Offensive Behaviour, Oxford: Hart Publishing.

Watt, N. (2012), 'David Cameron launches $£ 600 m$ “Big Society” fund', The Guardian, 4 April.

Wells, P. (2011), 'Prospects for a Big Society?', People, Place and Policy online, http://extra.shu.ac.uk/ppponline/issue_2_060711/article_5.html

Wacquant, L. (2008), Urban Outcasts: A Comparative Sociology of Advanced Marginality, Cambridge: Polity.

Wright, S. C., Brody, S. M. and Aron, A. (1996), 'Intergroup contact: still our best hope for improving intergroup relations', in C. S. Crandall and M. Schaller, M. (eds.), Social Psychology of Prejudice: Historical and Contemporary Issues, Kansas: Lewinian Press. 